\title{
LOS CONECTORES PRAGMÁTICOS COMO ÍNDICES DE MODALIDAD EN ESPAÑOL ACTUAL
}

\author{
ÁNGELA ARCE CASTILLO \\ (Universidad de Valladolid)
}

\begin{abstract}
RESUMEN
The present proyect studies those structures of the Spanish Language, that are not only linking elements in the speech, but also modalizers. They reflect their modal value and allow us to infer the type of relation between the speakers from the attitude they express when emitting the speech. We are talking about elements such as: really, in fact, exactly, precisely, of course, just so, sure enough, by the way, at least, in fact...

Being aware of the problems that come across with this study of modality, that is to say the attitude of the speaker with the listener and the speech. The molalizer plays its role, as part of the different modalities of the speech (indicates objectivity), as well as the modalities of the way to perform the speech (shows subjectivity). Therefore, the linguistic forms we are going to be dealing with, cxpress in one way or another, the opinion or intention of the speaker in relation with what he/she is speaking and/or his/her relation with the listener.

Moreover, the units we are going to study, are frecuently used in the conversation, however, their status in the different grammars is not well defined, there are formulas that we use to link the different parts of the speech. Besides that, all those formulas have certain modal value.

Furthermore, for the purpose of this study, a written corpus has been taken. That is the Spanish novel Caperucita en Manhattan by Carmen Martín Gaite. This novel has been chosen due to the fact that it is mainly written in dialogue and the language used is colloquial.
\end{abstract}




\section{Introducción}

Las unidades que analizaremos en este trabajo, además de funcionar como elementos de conexión en el discurso, son operadores modalizadores, reflejan su valor modal, nos permiten inferir el tipo de relación que se da entre los enunciantes, y la actitud que expresan al emitir sus enunciados. A partir de estos criterios intentaremos clasificar estas formas según su comportamiento $y$, así, incluirlas dentro del grupo de modalidades de la enunciación o de modalidades del enunciado.

Antes de comenzar a estudiar estos operadores solamente conviene recordar los problemas que plantea el estudio de la modalidad y la disparidad de opiniones que hay desde su propia definición, clases, hasta la variedad de procedimientos que existen a la hora de manifestar la modalidad. Tratando de ser muy escuetos consideramos que la modalidad es la actitud del hablante ante el enunciado y ante el oyente; y de esto surgirán dos tipos distintos de modalidad: la del enunciado y la de la enunciación. Y así, el hablante para expresar estas actitudes dispone de diferentes recursos lingüísticos como son: el modo y el tiempo verbal, la entonación, el orden de palabras, sustantivos, adverbios, interjecciones, adjetivos; estas tres últimas categorías funcionan muchas veces como conectores y, también consideramos como recurso que no hay que olvidar, ya que tiene su importancia, el contexto, y así lo expresa claramente Jiménez Juliál «cabe la posibilidad teórica de que una cierta modalidad, en una lengua determinada, carezca de un recurso concreto para su manifestación, siendo su reconocimiento verificado a través del contexto. De hecho se dan abundantes situaciones en las que sólo el contexto es el que nos permite inferir la modalidad de una expresión».

1.1. Las siguientes formas lingüísticas expresan de un modo u otro la opinión o intención del enunciador con respecto a lo que enuncia y/o su relación con el oyente. Por un lado existen operadores que podríamos incluir dentro de la modalidad de la enunciación, reflejan matices de subjetividad por parte del hablante, son los operadores que denotan deseo, temor, alegría, etc., o que de alguna manera implican al oyente en el acto comunicativo. $\mathrm{Y}$ por otro lado pertenecerían a la modalidad del enunciado los operadores que expresan lo verdadero, posible, contingente, dudoso con respecto a lo dicho. Indica objetividad. Por lo tanto comparando los operadores de ambos grupos se da una especie de contradicción ya que son elementos que se oponen en cuanto a lo que expresan; por un lado objetividad, hacen referencia a lo enunciado y, por otro subjetividad, forman parte del proceso de la enunciación. Pero son compatibles en cuanto que los operadores de ambos grupos poseen matices modales.

Dentro de los operadores que pertenecen a la modalidad de la enunciación existe también una cierta contradicción con elementos opuestos y lo que une a un

Vid. T. Jiménez Juliá, «Modalidad, modo verbal y modus clausal en español», en VERBA, 16, (1989), págs. 175-214. 
grupo de operadores es precisamente lo que los diferencia del otro grupo, por cjemplo los interrogativos del tipo: ¿no?, ¿eh?, ¿sabes?, ¿verdad? son compatibles contextualmente entre ellos porque todos esperan una respuesta por parte del oyente y además siempre son utilizados al final de una intervención, nunca pueden desarrollar la función, por ejemplo, de introductores de conclusión; todo esto que es lo que en cierto modo une a estas formas y es lo que hace que se opongan a elementos como: afortunadamente, ojalá, por lo menos, por desgracia, precisamente, por cierto... que pueden servir como introductores de conclusión y no esperan una respuesta directa del oyente y además entre estos últimos se podrían distinguir entre los que expresan deseo o valoración subjetiva de los hechos como son: ojalá, afortunadamente, por lo menos... y los que no manifiestan este tipo de actitudes como precisamente, por cierto...

Dentro de los operadores que pertenecen a la modalidad del enunciado lo que les hace compatibles lo hemos visto anteriormente y la contradicción que pueden mostrar es en cuanto al grado de verdad o de seguridad que indican los elementos dentro de un contexto determinado. Así, no expresa el mismo grado de seguridad la forma quizá que las formas efectivamente o exactamente, su oposición se basa en la escala que va de la duda a la seguridad rotunda. Después de haber realizado algunas pruebas objetivas de los operadores modalizadores analizaremos el comportamiento de cada uno de ellos dentro del grupo de modalidad al que pertenecen.

\section{Modalidades de la enunciación}

Con los operadores incluidos dentro de esta modalidad de la enunciación se manifiesta una valoración de los hechos, con matices más o menos claros de la reacción emocional que provocan. Pertenecen a la función expresiva o emotiva, a la modalidad de sentimiento. Dentro de las situaciones comunicativas que se producen la menos frecuente es la declaración, con predominio de la exhortación y la interrogación, pero todas con ciertos rasgos de subjetividad. Hay una serie de locuciones adverbiales, sintagmas preposicionales, expresiones, operadores en definitiva, que indican este tipo de modalidad.

2.1. Los siguientes operadores muestran la actitud del hablante y además realizan una pregunta, su modalidad de la enunciación por tanto se manifiesta en forma interrogativa. Implican en cierto modo al oyente con la pregunta que el hablante efectúa, no espera una respuesta, pero sí es un modo de hacer partícipe de la comunicación al oyente, es como una llamada de atención que justifica la presencia del oyente. Estos operadores son: ¿eh?, ¿sabes?, ¿no?, ¿verdad?... Muchas veces sirven como medio de conexión por parte del hablante, e incluso se pueden convertir en una muletilla, pero esas funciones no las trataremos aquí, aunque hay que considerar la variedad de usos que pueden tener. 
«- No - dijo-, es que se ha encaprichado de esta campanilla. Te gusta como suena ¿eh?... Espere» (p. 107).

«Lo menos que se puede exigir es que una tarta sepa igual todos los días, porque estamos en El Dulce Lobo, ¿no?» (p. 100).

«Lo han puesto ahí para que se crea que manda, pero no manda nada. ¿A ti te hace ilusión entrar, no?» (p. 118).

«Una nube de fotógrafos estaba pendiente de la llegada de aquella mujer que acababa de salir del coche negro...

— ¿Qué raro ese coche!, ¿verdad? —dijo la niña—» (p. 113).

« Mire esos raíles y el silloncito con el señor que va montado encima...! Parece un muñeco, ¿verdad?» (p. 120).

«¿Pero qué estás haciendo? ¡No des la vuelta, Peter, te he dicho! Estamos cerca de Battery Park, iverdad?» (p. 170).

La diferencia entre ¿no? y ¿verdad? es sólo de uso. Éstos surgen para referirse cl hablante al oyente, para exigir de éste su conformidad con su acto de comunicación, para pedir una confirmación de lo dicho, evidentemente no tiene nada que ver con otras modalidades. Que el enunciado sea asertivo, desiderativo o cxhortativo no importa, porque apelan a la enunciación, a la construcción del acto de hablar independientemente de la modalidad de lo dicho, del enunciado.

«No puedes hacerme compañía en mis recuerdos. Yo soy Gloria Star, la famosa cantante Gloria Star, ¿sabes?» (p. 56).

«- ¿Edgar Woolf? ¿El Rey de las Tartas? ¿Va a ir usted a casa de Edgar Woolf? Vive en uno de los apartamentos más lujosos de Manhattan, ¿lo sabía?» (pp. 86-87).

«-Pero el ferry a estas horas no funciona — comentó el taxista-. ¿No lo sabes?»(p. 184).

El valor de ¿sabes? está en comunicar algo que el oyente desconoce y debe saber, por eso se emite. Además de justificar la emisión del enunciado previo, esta forma es usada también por el hablante para conectar o mantener su comunicación con el oyente, para enfatizar elementos de su discurso que son planteados como información importante. Puede funcionar, como hemos vistó en los ejemplos anteriores, con la forma negativa y de tratamiento sin que su valor se altere.

También dentro de las modalidades de la enunciación, en este caso con forma declarativa y no interrogativa como las anteriores, podemos incluir la construcción verbal muy usada del tipo yo creo, en el sentido de dar una opinión personal, el punto de vista del propio hablante. Éste no pretende sumarse a una opinión general, sino que quiere dejar muy claro que es su opinión personal y que no sabe o no entra a decir, si puede ser compartida por los demás, es una forma de suavizar, de atenuar la afirmación. Aunque se diferencia notablemente de las 
demás formas que pretendemos estudiar, solamente veremos algún ejemplo debido a su frecuencia de uso para dar una opinión personal. Indica subjetividad.

«- Yo creo que hoy les ha salido algo mejor — decía una señora, entre sorbo y sorbo de té-》 (p. 100).

«Gracias, señora, pero los niños no saben lo que quieren.

- En eso no estoy de acuerdo, ya ve. Yo creo, por el contrario, que son los únicos que saben lo que quieren —contestó miss Lunatic $\gg($ p. 108).

2.2. En los siguientes ejemplos el hablante presenta los hechos introduciendo ågún juicio subjetivo o gramaticalmente expresado.

« ¿Sabes que eres muy lista?

— Eso dice mi abuela, y también que salgo a ella. Ojalá. Mi abuela sí que cs lista» (p. 134).

Los operadores del tipo: ojalá, por Dios... expresan deseo. Vemos en el ejemplo como se refleja la subjetividad por medio de ciertos rasgos gramaticales que son los que proporcionan dicho contenido. Se suelen utilizar con formas de subjuntivo que es un modo que de por sí manifiesta indeterminación, pero a veces debemos contar con diferentes recursos gramaticales que perfilen su sentido y para esto contamos con estos operadores.

En los siguientes ejemplos los hechos se presentan como deseados, pero no indican tanto un deseo en sí, como el cumplimiento de ese deseo y la consiguiente alegría del hablante. Tiene una carga modal expresiva.

«- Vaya, menos mal que me estoy divirtiendo con alguien — dijo miss Lunatic, mientras se rebuscaba un imperdible entre la faltriquera $\rightarrow$ (p. 136).

«Hurgó durante unos instantes muy nerviosa con los dedos metidos entre sus blancas mallas y la piel del tobillo, hasta llegar angustiada a la planta del pie. ¡Hasta allí se había escurrido la moneda mágica!, menos mal, ¡qué alivio!» (p. 182).

«Se había escurrido por una ranura entre el almohadón y el brazo de la butaca. Por fín la metió en la cerradura y levantó la tapa ondulada del mueble» (p. 60).

«Se paseaba como un oso enjaulado por su enorme despacho, encendía un pitillo detrás de otro y no paraba de mirar el reloj.

Por fin, subió con paso decidido la escalera de caracol que comunicaba con su dormitorio» (p. 103).

«El corazón le latía muy fuerte cuando, por fin, la encontró. Estaba cerrada con candado y pintada de gris. No podía ser otra» (p. 172).

Estas unidades suponen una valoración positiva, pero también el cumplimiento de un deseo. Pueden ir en cualquier posición, suelen ir entre pausas $y$ pueden referirse al hablante o a otro enunciador. 
Ninguna de estas unidades puede combinarse con una modalidad distinta de la exclamativa, ya que son indicadores de la misma. Aunque a veces no lleven los signos de exclamación, su sentido y entonación son exclamativos.

También pueden tener otros valores en el discurso, así, por fin en estos ejemplos se comporta como hemos señalado, pero puede aparecer como ordenador del discurso indicando por ejemplo el cierre de una serie. Por eso queremos dejar claro que podemos encontrar formas como las que estamos analizando en situaciones diversas y desarrollando funciones diferentes a las aquí tratadas.

2.3. Los operadores como por cierto, precisamente... sirven para precisar u ordenar cuando se da una digresión en el nivel discursivo, introducen una idea nueva si se produce algún distanciamiento entre la planificación discursiva iniciada y lo que sigue. Por cierto se usa como cambio de tema en algunas ocasiones y en otras como aclarador o recordatorio de hechos pasados. Implican de alguna manera al oyente en la comunicación.

«- Yo nunca. Sentar la cabeza debe ser aburridísimo. Por cierto, a ver si me mandas a Sara algún domingo, o la vamos a buscar nosotros, que Aurelio la quiere conocer» (p. 21).

«A ver si podemos tener tú y yo un poco de charla, hija. Por cierto, quería pedirte un favor, ahora que me acuerdo» (p. 59).

«- Gracias, hija. ¿Qué pies tan ligeros tienes! —dijo, mientras se volvía a poner el sombrero y se lo sujetaba fuertemente con ayuda de una de las bulandas que se había quitado del cuello-. Por cierto, ¿cómo te llamas?» (p. 115).

«A ella no le dan ni pizca de miedo los parques, baja mucho al de Morningside, y eso que dicen que es tan peligroso. ¿Por cierto, sabes tú si han cogido al vampiro del Bronx?» (p. 134).

«Entre estas reflexiones y la conversación con Peter, al que por cierto poca cosa logró sonsacar de la vida privada de su amo, transcurrió sin sentir el viaje de vuelta» (p. 175).

«Quick Plumber era el nombre del taller de fontanería que tenía montado el señor Allen con otro socio más joven. $Y$ precisamente este socio era el marido de la señora Taylor» (p. 31).

«- La dicha, Samuel, hay que pagarla con llanto. Se lo estaba diciendo a Lynda precisamente hoy a la hora de comer» (p. 74).

«-Esos dos extremos son difíciles de armonizar, señor. Perdone que se lo diga. Porque los niños suelen encapricharse precisamente de lo más peligroso» (p. 159).

Vemos en los ejemplos que el valor que tiene precisamente no es de algo que es necesario o que se precisa, sino que se utiliza siempre con relación a algo dicho anteriormente o ya conocido por el oyente, para retomar algo ya expuesto. 
2.4. Otros operadores dentro de esta modalidad son los evaluativos del tipo de: afortunadamente, por suerte, por desgracia, por lo menos, desgraciadamente, francamente, vamos...

«Luego fue a recoger el florero, temiéndose lo peor. Afortunadamente — ¡miranfú! - - había caído encima de la butaca y no se había roto» (p. 59).

«Mientras se rebuscaba un imperdible en la faltriquera-(...) Afortunadamente ha aparecido. No sé por qué los llaman imperdibles, si siempre se pierden» (p. 136).

«Luego venía un estallido más intenso que las iluminaba todas a la vez, mientras del interior de cada una empezaba a salir como un surtidor de pepitas de oro que se disparaba hacia el cielo oscurecido y caía luego en una cascada Ienta, chispeante y silenciosa.

Era francamente espectacular» (p. 95).

En el caso de francamente se nota también un cierto matiz de claridad, y sin dudas por parte del interlocutor. Y puede manifestar según los casos, actitudes ante la enunciación o el enunciado.

Estos elementos pueden tener movilidad, expresan por medio del operador actitudes subjelivas del hablante.

«Porque además, ¿tú cómo sabes que no son familia?

- Ni familia ni amigos. Me lo ha dicho la niña. Precisamente me ha venido intentando sonsacar a mí cosas del jefe, preguntándome que si me parecía buena persona. Pidiéndome informes, vamos. ¡A míl» (p. 179).

«-A la abuela de la niña, a la que vive ahí. ¿Tú la has visto?

- Yo no. ¿Cómo la voy a haber visto? ¿Por qué lo dices?

- Por saber cómo es, la pinta que tiene. Vamos, no me digas que no es raro que al jefe, que nunca sale, le dé hoy de repente por venir a este barrio a visitar a una gente que no le toca nada» (pp. 178-179).

El operador vamos también posee un cierto contenido de modalidad, sirve para recalcar lo que piensa el hablante, el matiz modal viene expresado al dejar clara la postura del que enuncia. Además de este valor modal, la forma vamos tiene muchos más valores ${ }^{2}$, puede rectificar, precisar, etc.

«Lo que veo es que te conoces Manhattan como la palma de la mano. ¿Llevas muchos años viviendo aquí?

—Por desgracia vivo en Brooklyn, hijo. ¿De qué te ríes?» (p. 170).

«-Parece que no, pero es un viaje. Un viaje de muchas millas. ¿A quién se le ocurre? ¡Si por lo menos siguiera viviendo en la avenida Cl» (p. 42).

2 Vid. L. Cortés Rodríguez, Sobre conectores, expletivos y muletillas en el español hablado, Ágora, Málaga, 1991. 
«- No te lo había querido decir para darte una sorpresa -añadió la señora Allen-. Y luego, al final, hay otra. Verás qué bien lo pasamos.

Pero no lo pasaron bien, por lo menos Sara» (p. 67).

«Pero estas estancias disponibles iban siendo cada vez menos, a medida que el negocio, en auge creciente, requería instalaciones más modernas, ornamentación puesta al día y maquinaria en continua renovación.

O por lo menos eso es lo que se empeñaba en creer míster Woolf» (p. 91).

«- ¿Me has oído, Peter? Dime, por lo menos en que barrio estamos. A mí me parece que te has equivocado, que vamos en dirección sur» (p. 169).

Éstos expresan una valoración subjetiva del hablante. Estamos ante la modalidad expresiva, de sentimiento, que puede ser manifestada bajo distintas formas como son: la declaración, exhortación o interrogación y por distintos medios, entre ellos todos los operadores comentados anteriormente. Con éstos no necesitamos tanto del contexto para averiguar la actitud del hablante, porque éstos destacan el sentido que el hablante quiere dar a su expresión.

\section{Modalidades del enunciado}

Este lipo de modalidad trata de indicar una actitud del hablante, actitudes internas que alectan al dictum. Los operadores que indican una actitud del hablante de necesidad, realidad, posibilidad, duda, certeza... son los que componen este tipo de modalidad del enunciado. Éstos son: ciertamente, sin duda, naturalmente, por supuesto, claro que... Pertenecen a la función representativa, a la modalidad de juicio. Se pueden dar las tres situaciones comunicativas, aunque la menos frecuente es la exhortación y hay un mayor predomino de la declaración. Es posible hacer una escala, como ha hecho ya Ana $M^{a}$ Barrenechea ${ }^{3}$, que va desde la inseguridad a la seguridad reforzada, con una zona neutra en la cual el modalizador aparece como una muletilla vacía de significación o como simple fórmula de sentido cortés (hacia el oyente) o de autoalirmación (hacia el hablante).

El hablante por medio de la lengua puede: a) Suspender la aserción, indicando inseguridad, huir de la responsabilidad, de los juicios emitidos, o mostrarlos como más o menos probables. Y b) Reforzar la aseveración, subrayando la absoluta certeza en lo que afirma.

a) Suspensión motivada de la aserción

Dentro de este grupo estarían operadores con matiz de probabilidad, de duda, del tipo de: tal vez, quizá, a lo mejor, seguramente...

Vid. A. M. Barrenachea, «Operadores pragmáticos de actitud oracional; los adverbios en -mente y otros signos», en Estudios lingüísticos y dialectológicos. Temas hispánicos, Hachette, Buenos Aires, 1979 , págs. 39-59. 
3.a.1. «A los niños lo que hay que hacer es contestarles a lo que preguntan, y si no se les quiere decir la verdad, porque a lo mejor no sabes tú misma lo que es la verdad, pues les cuentas un cuento que parezca verdad» (p. 20).

«-Y a mi qué me cuentas, chica. Habrán llamado y estarías comunicando. ¿No es tu madre? Pregúntaselo tú. A lo mejor le aburre que siempre le estés dando consejos, como si fuera una niña chica» (p. 27).

«- Está perdiendo oído por momentos — dijo la señora Allen, soltando un suspiro-.

- A lo mejor es que ha salido a dar una vuelta — dijo Sara— (p. 54).

«-Eso no acabo de entenderlo.

- Casi nadie; por eso digo que da poco resultado recetárselo a otro. A lo mejor un día de pronto, lo siente usted solo y lo entiende... En fin, ¿me da permiso para retirarme?» (p. 88).

« ¿Puedo pedirle que la deje venir a verlo mañana? Digo también por dentro, y asomarse a la terraza, y a lo mejor que le sirvieran una copita» (p. 153).

3.a.2. «Es un poco despistada. Dile que la he visto yo el otro día en el cajón de arriba del secreter.

- De acuerdo. Lo malo es si no me abre. Quizá no se fíc» (p. 160).

«Le encantaba el piso de la abuela Rebeca, tal vez por ser la única casa de Manhattan donde había entrado, y las historias que contaba la abuela Rebeca cuando estaba de buen humor, tal vez por ser las únicas interesantes que había escuchado jamás de labios de un ser vivo» (p. 39).

«Y míster Woolf está ansioso de soluciones, me temo que necesita que le manden. Tal vez porque está harto de hacerse obedecer» (p. 86).

«Neccsitaba darse un paseo. Tal vez se la volviera a encontrar en el parques (p. 105).

«- Las vi pasar - mintió-, y se me ocurrió que tal vez pudieran interesarle. Cuestión de olfato. Celebro haber acertado» (p. 121).

«Pensó vagamente que por aquellos barrios, tal vez no demasiado lejos de allí, existió en tiempos una librería que ella nunca había llegado a conocers (p. 183).

Vemos en los ejemplos anteriores que los operadores indican un mínimo de elección del hablante, éste se anima a manifestarse en favor o en contra de la verdad de un hecho.

3.a.3. «Que no, por favor, no faltaba más! - protestó la madre-. ¡Dásela Ray! Es de la scñora... Gracias, señora, pero los niños no saben lo que quicren...

- Además seguramente para usted sería un recuerdo» (p. 108).

«— ¿No sería miedo a la Libertad? —preguntó miss Lunatic solemnemente-

- Pues sí, seguramente sería eso - dijo tratando de que su voz sonara despreocupada- $\gg$ (p. 125). 
Seguramente en estos ejemplos no aparece como afirmación rotunda sino como una aproximación a lo que se quiere decir. Expresa más seguridad ante lo que comunica que los marcadores anteriores, pero nunca se utiliza para asegurar algo sin lugar a dudas, el hablante no intenta indicar certeza absoluta en su comunicación.

b) Refuerzo de la aseveración

No se puede determinar claramente el límite entre el grupo anterior y éste de los operadores que indican mucha más seguridad. Entre todas las unidades que hemos incluido dentro de los modalizadores existe una progresión y, a veces, es difícil situarlos justamente en el lugar de seguridad o inseguridad que tratan de expresar. Incluso dentro de este grupo hay diferencias en cuanto al grado de seguridad que expresan unos y otros.

Estos elementos refuerzan la verdad de lo afirmado en el discurso, con matices diversos que se apoyan sobre la seguridad del hablante, o agregan la cvidencia de los datos que ofrece la realidad. Son evidentes, juicios que no admiten dudas, manifiestan que lo dicho es obvio y con ellos suele darse por presupuesto el consenso del oyente por la experiencia, la información sobre la realidad, la capacidad para correlacionar datos y sacar conclusiones, etc.

3.b.l. Éstos son por ejemplo: por supuesto, lógico, evidentemente, claro que, naturalmente, seguro, desde luego...; afectan a todo o a parte del enunciado.

«Pero en cambio la mirada parecía de fiar; era evidentemente la de un hombre solitario y triste. De pronto sonrió. Y Sara le devolvió la sonrisa» (p. 148).

Se usa en casos en que se presupone que lo dicho es algo seguro para el hablante y el oyente, o está admitido por todos. Este operador generalmente va antepuesto aunque también puede ir pospuesto y en raras ocasiones intercalado.

«Espero que te portes bien.

- Naturalmente que se portará bien» (p. 76).

«-Eso es verdad. Hay que saber a qué atenerse.

- Naturalmente querida» (p. 100).

«Pero eso la haría completamente feliz. ¿Me lo concede?

- Naturalmente, por favor, yo mandaré a buscarla» (p. 153).

«Las calles céntricas, que naturalmente son las más atractivas, se convierten en un hormiguero humano que bulle y se empuja por las esquinas» (p. 165).

Se da como cosa esperable que el interlocutor participe de la misma opinión, por la información de los hechos que ya tiene o que se le ha suministrado. Presenta usos en los que los hechos son considerados previsibles, dado lo que se sabía de ellos. 
«Está bien. Mejor si es una marquesa. Y por supuesto, que les sirvan lo que quieran» (p. 122).

«— ¿No me ibas a invitar tú, hija mía?...

— Por supuesto, madame —dijo—» (p. 129).

$\ll_{i}$ Has intentado enamorarte en serio?

- ¿Y para qué, si todas me dejan?

- Desde luego, si llevas a una mujer a bailar y te pasas la noche hablándole de que la tarta de fresa te sale peor que la de chocolate» (p. 101).

«El sueño de Peter era verse protagonizando una película de persecuciones, donde el automóvil vencedor sortea audazmente toda clase de obstáculos... Lo suyo, desde luego, era el riesgo» (p. 164).

Como hemos dicho ya, no se emplea seguramente para la afirmación que no admite dudas, pero en cambio, si se usa con esa connotación la forma seguro.

«Su peculiar aspecto hacía imposible que nadie pudiera confundirla con otra mendiga cualquiera. Era ella, seguro, era la famosa miss Lunatic» (p. 80).

Mensajes con claro que, claro está... implican generalmente la confirmación de lo dicho antes, por el mismo informante o por el interlocutor. En ocasiones sirven como enfatizadores de la fuerza ilocutiva. Suelen ir entre pausas, y seguidos de algo que lo explica y corrobora. Veamos los siguientes ejemplos:

«Además, ¿no te ha dicho muchas veces que le gusta vivir sola?

- Claro que me lo ha dicho» (p. 18).

«Y como en los años en que un niño aprende a leer y a soñar es cuando lo desconocido se rodea más de magia, a Sara el barrio de Morningside le parecía entonces mucho más distante e irreal, la catedral de San Juan el Divino un castillo encantado, y aquella casa de Manhattan desde cuyas ventanas se divisaba un parque alargado y solitario, una casa de novela.

Claro que Sara, por muy lista que fuera, no había leído todavía ninguna novela» (p. 26).

«- ¿Te metes dentro?

- Claro que me meto. Me gustaría más ir por Central Park en coche de caballos» (p. 52).

«Sabes de sobra que jamás he conseguido que una mujer se enamorara de mí.

- Claro, porque eres un pelma. Y las mujeres necesitan que les hagan caso, que se dediquen a ellas» (pp. 101-102).

«- Además seguramente para usted sería un recuerdo.

— Sí, claro, pero el recuerdo lo voy a seguir teniendo igual» (p. 108). «Pero no se vaya, se lo ruego.

- ¡Claro que me voy! ¡Ahora mismo! (p. 128).

«- ¿Has leído Alicia en el país de las maravillas?

- Claro, muchas veces» (p. 137). 
«- ¿Como el del metro? - preguntó Sara fascinada-.

— Parecido, pero más estrecho, claro» (pp. 138-139).

«- Pero en el plano no viene eso.

— No, claro - contestó miss Lunatic-, en el plano no» (p. 140).

«- No puedo prometerle nada, míster Woolf —dijo-, hasta entender mejor lo que me pide, saber si puedo concedérselo... y, claro, también qué ventajas tendría para mí» (p. 152). sabes?

«- Pero el ferry a estas horas no funciona - comentó el taxista-. ¿No lo

— Sí, claro, ya lo sé» (p. 184).

3.b.2. Operadores del tipo realmente, de verdad, en efecto, la verdad, efectivamente, en realidad... indican que el hablante ha sopesado los hechos y deja constancia de que su opinión (segura o dudosa) viene después de haber meditado. Tienen un valor ponderativo y enfatizador. Suelen ir en posición inicial, a veces media, y en raras ocasiones ocupan la posición final.

«Era frecuente oír algún llanto desconsolado o presenciar alguna rabieta, porque se mostraban tan contrarios a apartarse de allí que muchas veces sus madres tenían que recurrir a la violencia para tirar de ellos. Realmente el olor a bollos, tartas y pasteles recién sacados del horno que invadía la calle en aquel tramo era tan apetitoso y tentador» (p. 93).

En los ejemplos en los que aparece en realidad apreciamos un cierto sentido de ambigüedad en el enunciado, corrige algo anterior presupuesto.

«Con este estrechamiento hacia arriba se lograba el efecto óptico deseado por el arquitecto que ideó el edificio: es decir que tuviera, como en realidad tenía, lorma de tarta» (p. 94).

«Esta terraza, lo más llamativo de todo el rascacielos, estaba coronada por adornos de grueso cristal policromado imitando diversas frutas, cada cual del color que en realidad le correspondía para lograr mayor verismo» (p. 94).

«Al parecer no era de las que, en realidad, tenían mayor aceptación y se había llegado a oír decir en más de una mesa no sólo que el producto había bajado de calidad, sino que nunca la tuvo» (p. 99).

Verdaderamente trata de enfatizar el sentido de lo enunciado, de que la afirmación sea más contundente. En este ejemplo vemos como pondera el sentido del adjetivo.

«Había despedido a sucesivos pasteleros y, según él, ninguno acertaba con una receta verdaderamente eficaz» (p. 99). 
Efectivamente, en efecto, de veras, la verdad... figuran en circunstancias en que se corrobora algo dicho antes por el hablante o por el interlocutor. Ambos suelen estar de acuerdo con la información.

«- ¿Pero qué te pasa, por favor, Sara? Estás temblando.

La niña, efectivamente, temblaba como una hoja» (p. 33).

«-Déjame. ¡Es que vamos por debajo del río!...

Había un tramo al principio del viaje en que el metro iba, efectivamente, por dentro del East River» (p. 49).

«La única coincidencia que podía servir de dato para relacionar la multinacional pastelera de ahora con aquella tiendecita olvidada era que conservaba el nombre con que ésta fue registrada por su primer dueño. Efectivamente, en honor al apellido de la familia, se seguía titulando The Sweet Woolf, o sea El Dulce Lobo» (p. 92).

«Cómo se nota que nunca has sabido lo que es tener un problema en scrio...!

Efectivamente, Edgar Woolf llevaba unos cuantos meses completamente obsesionado por culpa de la tarta de fresa» (p. 99).

«La alcantarilla roja apareció en seguida, y junto a ella estaba el poste. Lo palpó. Efectivamente, a media altura, se apreciaba al tacto la ranura por donde había que introducir la moneda verdosa» (p. 173).

«Y le daba rabia que el jefe de publicidad tuviera que contestar a aquellas Ilamadas telefónicas diciendo: 'Sí, sí, no se ha confundido, habla usted, en efecto, con el teléfono de El Dulce Lobo'» (p. 101).

«Parece que se quiere quedar con usted.

El niño, en efecto, se aferraba con todas sus fuerzas a un collar lleno de colgantes de diferentes formas y tamaños» (p. 107).

«- ¿De qué se ríe?

Míster Woolf, en efecto, sonreía divertido y satisfecho mirando a la niña» (p. 153).

«- Míster Woolf, parece que la señorita a quien acompaña Peter quiere decirle algo.

Sara, en efecto, había bajado la ventanilla y asomaba su rostro encendido de emoción» (p. 160).

«Acababa de desenvolver la tarta, quitándole el papel de plata, y el olor que desprendía era en verdad excelente» (p. 150).

«Pídeme lo que quieras, lo que quieras, a cambio. ¡Me tienes que ayudar! ¿Verdad que vas a ayudarme?» (p. 151).

«De verdad estás segura de que los hombres esos del cine no te vieron convertirte en estatua?

Miss Lunatic sonrió.

- Completamente segura» (p. 133).

«Pero así y todo, a veces hubiera sido preferible un guiño amistoso, un golpecito en la espalda y: 'no sé cómo lo ha logrado, Peter', 'es usted un artista', 'vamos a tomarnos un café en ese bar, Peter' o 'esta vez, de verdad, creí que nos llevaba por delante esa ambulancia'» (p. 163). 
«Estaba en uno de los anchos pasillos subterráneos que conducen a la salida. La verdad es que le apetecía poco entrevistarse con el Rey de las Tartas» (p. 109).

«Se quitó el sombrero, cayó de rodillas y miraba arrobado el pastel, aspirando sus efluvios con frenesí. La verdad es que su actitud empezaba a parecer algo inquietante» (p. 150).

«y a encender luces y correr las cortinillas y volverlas a descorrer. La verdad es que era muy simpática y muy graciosa» (p. 166).

La verdad es que tiene un carácter aclaratorio y a veces correctivo.

3.b.3. Mensajes con propiamente, exactamente, apuntarían un matiz de realidad. Aunque en ocasiones también sirven para corregir o precisar.

«El dormitorio de Edgar Woolf ocupaba el mismo espacio que su apartamento y pillaba exactamente debajo de él» (p. 102).

«- ¡Claro! -exclamó Sara muy excitada-. Es que es eso, eso exactamente fue lo que sentí» (p. 124).

«- Claro que hay otra forma de espantar el miedo, pero no es propiamente una receta, porque tiene que poner mucho de su parte el paciente» (p. 88).

Después de este análisis podemos apreciar que hay operadores que pertenecen al plano argumentativo, son indicadores de objetividad, precisan y concretan la idea de certeza, verdad, duda... del enunciado. Y por otro lado existen operadores que pertenecen al plano de la enunciación, indican las intenciones y actitudes del hablante con respecto a lo que enuncia y a su interlocutor, expresan subjetividad. Pero además de reflejar ese valor modal, estos operadores desarrollan una función de conexión, unión, de enlace entre los enunciados ${ }^{4}$.

\section{Referencias bibliográficas}

ACOSTA, L. (1984): «Las partículas modales del alemán y el español», en Studia Philologica Salmanticensia, 7-8, Universidad, Salamanca, págs. 7-41.

BARRENECHEA, A. M. (1979): «Operadores pragmáticos de actitud oracional: los adverbios en -mente y otros signos», en Estudios lingüísticos y dialectológicos. Temas hispánicos, Hachette, Buenos Aires, págs. 39-59.

BENVENISTE, E. (1977): Problemas de lingüística general, Siglo XXI, México, págs. 82-91.

CORTÉS RODRÍGUEZ, L. (1991): Sobre conectores, expletivos y muletillas en el español hablado, Ágora, Málaga.

4 Todos los ejemplos que hemos utilizado pertenecen a la obra Caperucita en Manhattan de Carmen Martín Gaite (ed.) Círculo de Lectores (1991). Los números que aparecen al final de cada ejemplo corresponden a la página de la obra mencionada. 
FUENTES RODRÍGUEZ, C. (1991): «Algunas reflexiones sobre el concepto de modalidad», en RESLA, 7, págs. 93-108.

JAKOBSON, R. (1975): Ensayos de lingiiística general, Seix Barral, Barcelona, págs. 307-316.

JIMÉNEZ JULIÁ, T. (1989): «Modalidad, modo verbal y modus clausal en español», en VERBA, 16, págs. 175-214.

LÁZARO CARRETER, F. (1984): Diccionario de términos filológicos, Gredos, Madrid.

OTAOLA OLANO, C. (1988): «La modalidad (con especial referencia a la lengua española)», en RFE, LXVIII, págs. 97-117.

ROCA PONS, J. (1974): Introducción a la gramática, Teide, Barcelona, págs. 292-295. 